European Journal of Social Psychology

Eur. J. Soc. Psychol. 35, 425-435 (2005)

Published online in Wiley InterScience (www.interscience.wiley.com). DOI: 10.1002/ejsp.257

\title{
Short Communication Affective responses to own violations of ingroup norms: The moderating role of norm salience
}

\author{
SANDRO COSTARELLI* \\ University of Trento, Italy
}

\begin{abstract}
The findings from two experiments support the argument that the salience of a relevant ingroup norm may moderate the affective consequences of one's normative violations. Participants' counternormative behaviour only influenced their self-reported affect under conditions of high norm salience. This relationship was mediated by participants' perceptions that their expression of ingroup favouritism was discrepant from a group norm of intergroup fairness. The presented evidence extends previous research in two ways. First, it qualifies prior work concerning the affective impact of normative 'discrepancy' on self-directed negative affect. Second, it shows that increased self-directed negative affect can be produced by deviations from the norms of a situationally salient and identityrelevant reference group. Copyright (C) 2005 John Wiley \& Sons, Ltd.
\end{abstract}

According to self-categorization theory (Turner, Hogg, Oakes, Reicher, \& Wetherell, 1987), when individuals categorize themselves as group members, they internalize, and conform to, the group's social norms. Indeed, any group-level response can be conceptualized as mediated by conformity to the content of relevant ingroup norms (Spears, Doosje, \& Ellemers, 1997). Support for this argument would be revealed, for example, by finding one's violation of relevant group norms linked to the subsequent experience of negative affect.

Indeed, Devine, Monteith, and their colleagues have demonstrated that violating standards of appropriate conduct is likely to result in self-directed negative affect (e.g. Devine \& Zuwerink, 1994; Devine, Monteith, Zuwerink, \& Eliot, 1991; Monteith, 1993; Monteith, Devine, \& Zuwerink, 1993; Zuwerink, Devine, Monteith, \& Cook, 1996). According to these researchers, this phenomenon is driven by a 'discrepancy' between how one thinks one should have behaved according to relevant normative standards, and how one actually behaved (cf. Higgins, 1987). However, according to the focus theory of normative conduct (Cialdini, Kallgren, \& Reno, 1991; Cialdini, Reno, \& Kallgren, 1990), a norm does not direct behaviour unless it is made salient in the situation. Self-categorization theory (e.g. Terry \& Hogg, 1996; Turner et al., 1987) also suggests that relevant group norms must be salient before ingroup standards will affect individual behaviour.

*Correspondence to: Sandro Costarelli, Department of Cognitive Sciences and Education, University of Trento, via M. Del Ben, 5 I-38068 Rovereto (TN), Italy. E-mail: sandro.costarelli@unitn.it

Copyright (C) 2005 John Wiley \& Sons, Ltd.

Received 3 June 2004

Accepted 11 January 2005 
Based on this prior work, we argue that the relative salience of an ingroup norm (e.g. to treat ingroup and outgroup members equally) will moderate the effects of counternormative behaviour (e.g. favouring the ingroup) on subsequent affect. We further propose that the effect of norm salience on emotional reactions to counternormative behaviour will be mediated by the perceived discrepancy between the group norm and one's behaviour. In these studies, we measure positive affect (e.g. friendly and glad) and self-directed negative affect (e.g. guilty and disappointed with myself). Monteith (1996) finds both types of prejudice-related affect to be uniquely associated with normative discrepancies. In the first study, we tested whether salience of a relevant norm moderates the potential positive and negative affective impact of counternormative behaviour (Higgins, 1987). In the second study, we tested a moderated-mediation hypothesis. We predicted that under conditions of high(er) but not low(er) salience of a relevant norm (i.e. intergroup non-differentiation or fairness), participants' perceived discrepancy from this norm would mediate the effects of counternormative behaviour (i.e. intergroup differentiation or bias) on subsequent positive and negative affect.

\section{STUDY 1}

\section{Method}

\section{Participants and Design}

Sixty female and 61 male high-school students $(N=121)$ volunteered to participate in this experiment and were randomly allocated to conditions. Participant gender was similarly distributed across conditions. There were no significant effects for gender. Therefore, we will not discuss this variable further.

The study had a one-factor design with norm salience (low vs. high) as the independent variable. For this study, we capitalized upon a linguistically-defined naturally occurring ingroup in selecting our participants: the participants, or ingroup members, belonged to the Italian-speaking linguistic population group living in Italian South Tyrol; the target outgroup was defined as members of the German-speaking linguistic population group living in the same territory. Prior research shows that the members of these groups perceive themselves as having roughly equal group status (cf. Capozza \& Manganelli-Rattazzi, 1999). However, it is important to note that German-speaking South Tyrolers did not have access to jobs in public administration during the Fascist dictatorship. Since then, in Italian South Tyrol, allocation of public resources between the local linguistic groups must be equal by law. Furthermore, elimination of intergroup prejudice and discrimination has become one of the key aims of local educational and social policies.

\section{Procedure}

Before the start of a regular academic lecture, an experimenter invited students to participate in the study. The experimenter introduced himself as a university student coming from outside of South Tyrol. He explained that his student job was to recruit people to complete the many questionnaires that were mailed to him by various national survey institutes. He also stated that he was only responsible for data collection, and was supposed to mail back the questionnaires for data input the next day. We designed this introduction to minimize any perceptions of pressure to respond in line with the expectations of the experimenter. 
Participants then received a booklet containing an introduction sheet and a questionnaire. In the introduction sheet, the study was presented as 'part of a larger research project investigating European students' attitudes towards various social objects'. Then, a summary of the procedure followed. Afterwards, participants individually completed the questionnaire. After all participants had completed the questionnaire, they were debriefed and thanked.

To make participant's ethnic group membership salient, identification with the Italian-speaking linguistic population group of South Tyrol was measured first. Participants randomly assigned to the high salience norm experimental condition read a direct request to complete the subsequent intergroup evaluation task in line with the ingroup norm prescribing that, in Italian South Tyrol, one should not favour members of one's own ethnic group over people of different ethnic backgrounds. Participants assigned to the low salience norm condition only were asked to complete the task.

Then, participants were presented with a task (i.e. intergroup evaluation) that was relevant to the manipulated norm ('Now we will ask you to engage in two tasks involving the members of two groups: Italian-speaking South Tyrolers and German-speaking South Tyrolers. As you complete these tasks, please do not think about one specific person belonging to these groups, but rather to these groups in general'). Immediately afterwards, participants completed a measure of affect. Subsequently, participants' perceived salience of the manipulated ingroup norm as they were completing the tasks was assessed. We also assessed participants' perceived ingroup endorsement of the manipulated ingroup norm.

\section{Measures}

All ratings were made on 5 -point scales $(1=$ not at all, $5=$ very much $)$.

Ingroup Identification Participants completed Doosje, Ellemers, and Spears' (1995) four-item ingroup identification scale (e.g. 'I see myself as a [member of Group X]', 'I am pleased to be a [member of Group X]'). Scale scores were computed by averaging responses across items (Cronbach's $\alpha=0.83$ ).

Intergroup Differentiation Intergroup differentiation was measured by an intergroup evaluation task. Participants rated members of the ingroup and the outgroup on four trait adjective items that appeared in random order on a list (likeable, funny, attractive, admirable). Rating order of ingroup and outgroup was counterbalanced within conditions. There were no significant effects for rating order. Therefore, we will not discuss this variable further.

Affect Participants' affective state was assessed using some of those affect items that loaded uniquely on the factors that in previous work on prejudice-related affect (e.g. Devine et al., 1991; Monteith et al., 1993; Zuwerink et al., 1996) was interpreted as reflecting distinct positive and negative affective states (each measured with three items). Specifically, these were negative feelings directed at the self (e.g. guilty and disappointed with myself; $\alpha=0.91$ ) and positive affect (e.g. friendly and glad; $\alpha=0.85$ ). Participants were asked to report the extent to which each of the emotional adjectives presented as part of a list of randomly ordered items, applied to how they were feeling after completing 'the prior tasks' (intergroup evaluation). Participants were instructed not to think too much about their ratings and instead to give quick, gut-level responses.

Manipulation Check Participants answered 'As you were completing the above tasks, to what extent did you feel as relevant the group standard prescribing that one should be equally concerned for people 
of ethnic background other than one's own living in Italian South Tyrol as for fellow members of one's linguistic group?'.

Ingroup Norm Endorsement Participants answered 'To what extent do you get the impression that Italian-speaking people, students included, living in Italian South Tyrol are equally concerned for people of different ethnic backgrounds living on the local territory as they are for fellow members of their linguistic group?'.

\section{Results}

First, we checked levels of ingroup identification and norm agreement to determine whether participants agreed with our understanding of the group context. Participants' ingroup identification was indeed quite strong $(M=3.12, S D=1.35)$. Participants also perceived the intergroup fairness norm as being endorsed quite strongly by ingroup members $(M=3.69, S D=0.70)$. Finally, in two separate one-way analyses of variance (ANOVAs), we checked whether ingroup identification and ingroup norm endorsement varied across norm salience conditions. No effects were found, $F \mathrm{~s}<1.70$, $p s>0.11, \eta^{2} \mathrm{~s}<0.04$.

\section{Manipulation Check}

We checked the extent to which participants had perceived the prescriptions of the manipulated ingroup norm (i.e. intergroup fairness) as being salient as they were completing the intergroup evaluation task. Participants in the high salience condition reported the intergroup fairness norm to be much more salient $(M=3.43, S D=1.20 ; N=60)$ than participants in the low salience condition $(M=2.14, S D=1.17 ; N=61), F(1,120)=6.48, p<0.05, \eta^{2}=0.11$. This confirmed that the manipulation of norm salience had the desired effect.

\section{Affect}

For each target group, separate indexes of participants' evaluation of the ingroup and the outgroup were constructed. We averaged responses on the respective adjective items $(\alpha \mathrm{s}$ : ingroup $=0.73$, outgroup $=0.84$ ). An index of ingroup favouritism was computed for each participant. To this end, we subtracted the evaluations of the outgroup from those of the ingroup $(M=0.15, S D=1.08)$. Preliminary analyses also indicated that ingroup favouritism was not affected by the manipulation of norm salience, $t(120)=1.00, p>0.61, \eta^{2}=0.01$. This provided methodological justification for the test of norm salience as a moderator of the impact exerted by participants' ingroup favouritism upon following reported affect. To this end, we used hierarchical multiple regression. Ingroup favouritism (treated as continuous variable) and norm salience (treated as categorical independent variable; effect coding: ' -1 ' and ' +1 ') were considered as predictors. Specifically, in the model, we entered mean-centred scores for these variables into Step 1, and the interaction term into Step 2 (cf. Aiken \& West, 1991). Two separate regression models were tested with self-directed negative affect and positive affect as dependent variables, respectively, and with norm salience and ingroup favouritism as predictors.

Step 1 of the regression analysis revealed that self-directed negative affect was stronger in the high salience than in the low salience condition $(\beta=0.34, t=2.76, p<0.01)$. Additionally, increases in ingroup favouritism were found to be associated with increases in reported self-directed negative affect $(\beta=0.23, t=2.08, p<0.05)$. The final equation was statistically significant $(F=6.45, p<0.01)$, with the two predictors accounting for $16 \%$ of the adjusted variance in self-directed negative affect. In 
the second step, the regression coefficient for the two-way interaction term was statistically significant $(\beta=0.27, t=2.03, p<0.05)$ and its addition to the equation resulted in a statistically significant improvement in prediction over and above the effects of the other terms $\left(R^{2}\right.$ change $=0.08, F$ change $=4.98, p<0.01)$. The final equation was statistically significant $(F=5.04, p<0.01)$, with the predictors accounting for $23 \%$ of the adjusted variance in self-directed negative affect.

Step 1 of the regression analysis revealed that positive affect was weaker in the high salience than in the low salience condition $(\beta=-0.28, t=-2.22, p<0.05$.). Increases in ingroup favouritism also were found to be associated with decreases in reported positive affect $(\beta=-0.25, t=-2.02$, $p<0.05)$. The final equation was statistically significant $(F=5.16, p<0.01)$, with the two predictors accounting for $13 \%$ of the adjusted variance in positive affect. In the second step, the regression coefficient for the two-way interaction term was statistically significant $(\beta=0.35, t=2.87, p<0.01)$ and its addition to the equation resulted in a statistically significant improvement in prediction over and above the effects of the other terms $R^{2}$ change $=0.11, F$ change $=8.21, p<0.01$ ). The final equation was statistically significant $(F=6.62, p<0.001)$, with the predictors accounting for $23 \%$ of the adjusted variance in positive affect.

Further analyses were aimed at decomposing the nature of the interaction that emerged in the two analyses. To this end, we conducted and then compared the results of two separate sets of simple regression analyses, one for participants under conditions of low salience and one for participants under conditions of high salience of the relevant norm. This procedure allowed us to examine the influence of ingroup favouritism on reported self-directed negative affect and positive affect within each of these two conditions. When norm salience was high, a main effect of ingroup favouritism was observed for self-directed negative affect and positive affect, $t \mathrm{~s}>12.211, p \mathrm{~s}<0.05$, adjusted $R^{2} \mathrm{~s}>10.18 \mathrm{l}$. As predicted, the greater the ingroup favouritism the stronger self-directed negative affect $(\beta=0.48)$ and the weaker positive affect $(\beta=-0.45)$. In contrast, for participants under conditions of low norm salience, ingroup favouritism did not predict self-directed negative affect and positive affect, $\beta \mathrm{s}=|0.13|, t \mathrm{~s}<|1|, p \mathrm{~s}>0.55$, adj. $R^{2} \mathrm{~s}<|0.03|$.

\section{Discussion}

As predicted, increases in participants' ingroup favouritism (i.e. evaluations that did not comply with the relevant norm of intergroup fairness) were associated with increases in self-directed negative affect and decreases in positive affect in the high norm salience experimental condition. These results provide some clear, albeit preliminary, support for our argument that counternormative behaviour only leads to decreased psychological well-being when the relevant group norm is salient.

One limitation of Study 1, however, was that we did not assess directly the degree of normative discrepancy, the factor we hypothesize to underlie the observed affective consequences of norm salience. Further, the existing intergroup competition over resources might have biased the test of our hypotheses. As Sherif and others argue, the tendency to favour the ingroup becomes pervasive to the extent that ingroup-outgroup competition over resources is perceived to be as high (Sherif \& Sherif, 1953; Sherif, Harvey, White, Hood, \& Sherif, 1961; see also LeVine \& Campbell, 1972).

\section{STUDY 2}

Study 2 addressed three goals. First, we wanted to replicate the pattern of results found in Study 1. Second, we tested whether perceived normative discrepancy mediates the observed effects of counternormative behaviour on subsequent affect. In this study, we asked participants to rate the 
extent to which their evaluative ratings were discrepant from the intergroup fairness norm. Finally, we used a different target group, namely, African immigrants. We did not think that Italian-speaking South Tyrol residents would view these immigrants as competing for resources in the same way that they might view German-speaking South Tyrol residents.

\section{Method}

\section{Participants and Design}

Seventy-three female and 46 male Italian-speaking high-school students $(N=119)$ volunteered to participate in this experiment, and were randomly allocated to conditions. Participant gender was similarly distributed across conditions. There were no significant effects for gender, so we will not discuss this variable further.

As in Study 1, the participants, or ingroup members, belonged to the Italian-speaking linguistic population group living in Italian South Tyrol. The design was also identical to Study 1, with one difference. Specifically, the target outgroup was defined as immigrants from Africa living in the same territory as the participants. A different sub-sample $(N=30)$ taken from the same population of undergraduate students perceived immigrants from Africa living in the same territory as not competing over resources with the ingroup (perceived ingroup-outgroup competition over resources: $M=0.27$, $S D=0.81 ; t=0.16, p>0.20)$. As in Study 1, rating order of the target groups was counterbalanced within conditions. There were no significant effects for rating order, so we will not discuss this variable further. Operationalization and manipulation of norm salience were the same way as in the preceding study.

\section{Procedure and Measures}

The procedure was identical to Study 1, with one difference. Specifically, after self-reporting their affect, participants' perceived normative discrepancy was assessed. To this end, they were asked the extent to which their intergroup evaluation had been "in line with the norm prescribing that one should not prejudicially favour members of one's ethnic group over people of different ethnic background living in Italian South Tyrol'. Except for the latter item, all measures were identical to those used in Study 1 . Responses were expressed on 5 -point Likert scales $(1=$ not at all, $5=$ very much $)$.

\section{Results}

First, we checked levels of ingroup identification and norm agreement to determine whether participants agreed with our understanding of the intergroup context. Participants' ingroup identification was indeed quite strong $(M=3.95, S D=1.01)$. Participants also perceived the norm as being endorsed quite strongly by ingroup members $(M=3.82, S D=0.83)$. Finally, in two separate one-way ANOVAs, we checked whether ingroup identification and ingroup norm endorsement of the relevant norm varied across norm salience conditions. No effects were found, $F_{\mathrm{s}}<2.38, p \mathrm{~s}>0.10, \eta^{2} \mathrm{~s}<0.06$.

\section{Manipulation Check}

We checked the extent to which participants had perceived the prescriptions of the manipulated ingroup norm (i.e. intergroup fairness) as being salient when they were completing the intergroup 
evaluation task. Participants in the high salience condition reported the intergroup fairness norm to be much more salient $(M=4.43, S D=1.20 ; N=60)$ than participants in the low salience condition $(M=2.00, S D=1.38 ; N=59), F(1,118)=9.61, p<0.01, \eta^{2}=0.14$. This confirmed that the norm salience manipulation had the desired effect.

\section{Affect}

For each target group, separate indexes of participants' evaluations were constructed by averaging responses on the respective items $(\alpha \mathrm{s}$ : ingroup $=0.72$, outgroup $=0.85)$. We computed an index of ingroup favouritism by subtracting the evaluations of the outgroup from those of the ingroup $(M=0.51, S D=0.10)$. Preliminary analyses indicated that participants' ingroup favouritism was not influenced by the manipulation of norm salience, $t(118)=1.19, p>0.24, \eta^{2}=0.03$. This provided methodological justification for the test of norm salience as a moderator of the impact exerted by ingroup favouritism upon following reported affect. To this end, we used hierarchical multiple regression. Ingroup favouritism (treated as continuous variable) and norm salience (treated as categorical independent variable; effect coding: ' -1 ' and ' +1 ') were considered as predictors. Specifically, in the model, we entered mean-centred scores for these variables into Step 1, and the interaction term into Step 2 (cf. Aiken \& West, 1991). This model was tested first with positive, and then with self-directed negative, affect as dependent variables.

Regarding positive affect, this analysis revealed no reliable effects, $\beta \mathrm{s}<-0.05, t \mathrm{~s}<-0.50$, $p \mathrm{~s}>0.62$, adj. $R^{2} \mathrm{~s}<-0.03, F \mathrm{~s}<0.11, p \mathrm{~s}>0.95$. With respect to self-directed negative affect, an interaction of ingroup favouritism and norm salience on reported self-directed negative affect was found, $\beta=0.24, t=2.11, p<0.05$, adj. $R^{2}$ change $=0.04, F$ change $=4.71, p<0.05$. There were no other effects, $\beta \mathrm{s}<0.06, t \mathrm{~s}<0.55, p \mathrm{~s}>0.58$, adj. $R^{2}=0.02, F=0.16, p>0.85$.

Further analyses were aimed at decomposing the nature of this interaction. Specifically, we conducted and then compared the results of two separate sets of simple regression analyses, one for participants under conditions of low salience and one for participants under conditions of high salience of the relevant norm. As expected, in the high salience condition, increases in reported self-directed negative affect were associated with increases in ingroup favouritism, $\beta=0.33, t=2.06, p<0.05$, adj. $R^{2}=0.11$. In contrast, and also in line with predictions, in the low salience condition ingroup favouritism did not significantly predict self-directed negative affect, $\beta=0.13, t=0.86, p>0.40$, adj. $R^{2}=0.01$.

\section{Normative Discrepancy}

Building on previous research by Devine et al. (1991) and their colleagues (as discussed above), we conducted further analyses to test our moderated-mediation hypothesis that under conditions of high but not low salience of the relevant norm the impact of ingroup favouritism on self-directed negative affective is mediated by perceived normative discrepancy $(M=3.37, S D=1.60$, across conditions). We used the same approach that we followed in the previous analysis to explore whether ingroup favouritism and norm salience predicted normative discrepancy. Although there was no statistically significant influence of norm salience $(\beta=0.13, t=1.47, p>0.14)$, increased ingroup favouritism was statistically significantly associated with increases in perceived discrepancy from the group norm $(\beta=0.49, t=5.37, p<0.001)$.

This finding ruled out the possibility that the degree of normative discrepancy varied across experimental conditions. The final equation was statistically significant $(F=16.19, p<0.001)$, with the two predictors accounting for $25 \%$ of the adjusted variance in normative discrepancy. In the second 
step, the regression coefficient for the two-way interaction term was statistically significant $(\beta=0.25$, $t=2.48, p<0.05)$ and its addition to the equation resulted in a statistically significant improvement in prediction over and above the effects of the other terms (adj. $R^{2}$ change $=0.06, F$ change $=6.13$, $p<0.05)$. The final equation was statistically significant $(F=4.50, p<0.05)$, with the predictors accounting for $10 \%$ of the adjusted variance in perceived normative discrepancy. Thus, as with the measure of self-directed negative affect, participants' ingroup favouritism predicted perceived normative discrepancy differentially as a function of norm salience.

Further analyses were aimed at decomposing the nature of this interaction. To this end, we conducted and then compared the results of two separate sets of simple regression analyses, one for participants under conditions of low salience and one for participants under conditions of high salience of the relevant norm. This procedure allowed us to examine the influence of ingroup favouritism on perceived normative discrepancy within each of these two conditions. These analyses revealed that the nature of this interaction was similar to the one observed for the measure of self-directed negative affect. Specifically, in the high salience condition, increases in perceived discrepancy were associated with increases in ingroup favouritism, $\beta=0.30, t=3.94, p<0.05$, adj. $R^{2}=0.31$. In contrast, in the low salience condition, ingroup favouritism did not significantly predict perceived discrepancy, $\beta=0.19, t=0.99, p>0.33$, adj. $R^{2}=0.22$.

\section{Mediational Analysis}

These findings are statistically consistent with the argument that the effect of ingroup favouritism on self-directed negative affect may be mediated by perceived discrepancy with the relevant norm under conditions of high but not low norm salience. To examine this possibility, we tested whether controlling for normative discrepancy eliminated the observed interaction for self-directed negative affect. We used perceived normative discrepancy and ingroup favouritism (both treated as continuous variables) as well as manipulated norm salience (treated as categorical independent variable; effect coding: ' -1 ' and ' +1 ') as predictors and self-directed negative affect as the outcome variable in hierarchical multiple regression equations. We entered mean-centred scores into Step 1, the two-way interaction terms into Step 2, and the three-way interaction into Step 3 (cf. Aiken \& West, 1991).

With respect to self-directed negative affect, in a first model not including normative discrepancy as a predictor, an interaction of ingroup favouritism and norm salience on reported self-directed negative affect was found, $\beta=0.24, t=2.11, p<0.05$, adj. $R^{2}$ change $=0.04, F$ change $=4.71, p<0.05$, and no main effects, $t \mathrm{~s}<0.55, p \mathrm{~s}>0.58$, adj. $R^{2}=0.02, F=0.16, p>0.85$.

Unlike the findings from the respective preceding analyses (as reported earlier), analyses conducted on a second model including normative discrepancy as a predictor revealed that the norm salience by ingroup favouritism interaction no longer contributed significantly to the prediction of self-directed negative affect, $\beta=0.13, t=1.78, p>0.08$, while a main effect of normative discrepancy was statistically significant, $t=2.73, p<0.01$, adj. $R^{2}$ change $=0.04, F$ change $=4.71, p<0.05$. The stronger participants' perceived discrepancy with the relevant norm the greater their reported selfdirected negative affect $(\beta=0.37)$. No other reliable effects were found, $\beta \mathrm{s}<0.06, t \mathrm{~s}<1.42, p \mathrm{~s}>0.10$. Thus, participants exhibited a decreased level of well-being to the extent that they perceived their ingroup favouritism to be discrepant with the relevant norm. However, this only occurred when salience of the norm that was relevant to the task they had just completed was high, compared to when salience of the relevant norm was low. These findings suggest that the effect of ingroup favouritism on self-directed negative affect was indeed mediated by participants' perceptions of normative discrepancy.

Path analyses (Baron \& Kenny, 1986) conducted separately for participants under high and low norm salience conditions support the same conclusion. Specifically, for participants in the high norm 
salience condition, one simple regression analysis revealed a significant effect of ingroup favouritism (i.e. the predictor) on perceived discrepancy (i.e. the mediator), $\beta=0.30, t=3.94, p<0.05$, adj. $R^{2}$ $=0.31$. Additionally, for participants in this condition, from Step 1 of a different regression analysis a main effect of ingroup favouritism on self-directed negative affect (i.e. the criterion) emerged as statistically significant (as reported earlier), $\beta=0.33, t=2.06, p<0.05$, adj. $R^{2}=0.11$. When the effect of discrepancy was controlled for by entering it into Step 2 of the latter regression model, the path from discrepancy to self-directed negative affect was significant, $\beta=0.35, t=2.16, p<0.05$. However, the direct path from ingroup favouritism to self-directed negative affect was no longer reliable, $\beta=0.01, t=0.41, p>0.68$. A statistically significant improvement in prediction of the criterion resulted over and above the effect revealed in Step $1\left(\operatorname{adj} . R^{2}\right.$ change $=0.09, F$ change $=4.68$, $p<0.05)$. The final equation was statistically significant $(F=4.20, p<0.05)$, with the predictors accounting for $11 \%$ of the adjusted variance in self-directed negative affect. Replicating results from the previous analysis, this finding suggests that the effect of ingroup favouritism on self-directed negative affect was indeed mediated by participants' perceptions of normative discrepancy. Further analyses indicated that reverse mediation (i.e. self-directed negative affect as mediating the ingroup favouritism-discrepancy relation) did not occur.

For participants in the low norm salience condition, the regression of ingroup favouritism on perceived discrepancy was not significant $\left(\beta=0.19, t=0.99, p>0.33\right.$, adj. $\left.R^{2}=0.03\right)$, and the respective paths both from ingroup favouritism and from discrepancy to self-directed negative affect were not reliable either, $\beta \mathrm{s}<0.13$, ts $<0.69$, $p \mathrm{~s}>0.49$, adj. $R^{2}$ s change $<0.02$, Fs change $<0.48, p \mathrm{~s}>0.49$.

\section{Discussion}

As predicted, when an intergroup fairness norm is made salient, participants who expressed more ingroup favouritism also felt more guilty and disappointed with themselves because they viewed their behaviour as more discrepant from the group norm. These results also confirm that this phenomenon occurs in intergroup contexts where ingroup-outgroup competition over resources is not at stake. Most important, these results provided further support for our argument that when a relevant norm is salient, one's own acts violating the prescriptions of that norm (a) may elicit a negative affective state directed at the self, and (b) this latter stems from the perception of being normatively discrepant.

\section{GENERAL DISCUSSION}

As predicted, we demonstrated that (a) salience of a relevant norm moderates the impact of one's counternormative behaviour on one's affective state (Studies 1 and 2), and (b) in turn such an effect is mediated by one's perception of being discrepant with relevant normative prescriptions (Study 2).

The results are consistent with the argument that normative discrepancies influence affect (Devine et al., 1991; Devine \& Zuwerink, 1994; Monteith, 1993; Monteith et al., 1993; Zuwerink et al., 1996) and that norm salience moderates the affective consequences of normative discrepancies (Cialdini et al., 1990, 1991; Terry \& Hogg, 1996; Turner et al., 1987). Finally, our findings support the argument that group-level responses should be conceptualized as mediated by conformity to the content of relevant ingroup norms (Spears et al., 1997).

These results extend previous work in two important ways. First, they demonstrate that the salience of a situationally relevant norm may moderate the affective impact exerted by perceptions of psychological discrepancy arising from one's non-conformity to normative prescriptions. Second, these findings extend previous work by showing that the observed negative affective consequences may 
also be a response to one's perceived discrepancy with the norms of a situationally salient and identityrelevant reference group, rather than only with individually held standards. Support for this notion was provided by the fact that, across the two presented studies, participants' ingroup identification and perceived ingroup endorsement of the relevant norm were found to be consistently strong.

Previous research on norm discrepancy and affect is based on the assumption that the affective consequences of people's behaviour can be affected only by individual standards for conduct. As opposed to 'other-based' standards (i.e. social norms), only 'self-based' ones are truly internalized by individuals. Hence, this individualistic line of research has not explicitly investigated the issue of whether such affective consequences are in fact dependent from any important socially-based element that characterizes the social context where the effects of individuals' normative discrepancy are displayed.

The present research attempted to fill in this gap of knowledge. To this end, it was focused on norm salience as one such potentially important element. Most notably, in the present work, effects were found on the very same affective dependent variables that have been typically used in previous research on discrepancy-related affect. Indeed, the more socially-based approach adopted by the current investigation fits in within a more recent research line investigating how people may experience negative emotions as a result of their group membership (cf. Smith, 1993). Specifically, in this novel research line, it is argued that people may experience emotions both as an individual and as a group member, depending on which level of the self (personal or social, respectively) is situationally made salient.

However, it could be argued that our affective measures were indeed focused on the individual person. Hence, claiming that our participants' affective self-reports represent an example of groupbased emotions would be unwarranted. Still, it is important to note that our participants were presented with an ingroup identification scale before the manipulation of norm salience took place. Therefore, it is conceptually very likely that the relevant ingroup was situationally salient. Furthermore, in both studies, participants' ingroup identification was found to be fairly high. Hence, it is theoretically likely that participants self-stereotyped themselves in terms of a reference group. In turn, according to selfcategorization theory, this suggests that participants were likely to be more attuned to ingroup rather than personal norms for deriving their standards of appropriate intergroup conduct, as they completed the experimental task.

Arguably, in turn this latter conclusion might, on the surface, appear to be inconsistent with the basic assumption underlying prior individualistic work on discrepancy-related affect by Devine, et al. (1991) and their colleagues. However, one way to integrate these two lines of research is to consider the suggestion from self-categorization theory that individuals are motivated to be sensitive to the content of socially shared norms and individually held standards. Specifically, according to this theoretical framework, this is so because acting in accordance with social norms expresses one's social identity, assuming some degree of identification with one's own group. Indeed, reactions to individual standards and social norms are equally possible, depending on the level (personal or social, respectively) of their own identity to which people are attuned in a given situation.

\section{ACKNOWLEDGEMENTS}

The author would like to thank two anonymous reviewers for their helpful suggestions, and particularly Heather Smith (the editor) for her stimulating and thoughtful comments on a previous version of this article. Heartfelt thanks are also due to Marilynn Brewer (Ohio State University) for providing her feedback and encouragement on the original version of this article. 


\section{REFERENCES}

Aiken, L. S., \& West, S. G. (1991). Multiple regression: Testing and interpreting interactions. Newbury Park, CA: Sage.

Baron, R. M., \& Kenny, D. A. (1986). The moderator-mediator variable distinction in social psychological research: Conceptual, strategic, and statistical considerations. Journal of Personality and Social Psychology, 51, 1173-1182.

Capozza, D., \& Manganelli-Rattazzi, A. M. (1999). Stereotypes and attribution processes in a multi-ethnic province. Journal of Community and Applied Social Psychology, 9, 231-236.

Cialdini, R. B., Reno, R. R., \& Kallgren, C. A. (1990). A focus theory of normative conduct: Recycling the concept of norms to reduce littering in public places. Journal of Personality and Social Psychology, 58, 1015-1026.

Cialdini, R. B., Kallgren, C. A., \& Reno, R. R. (1991). A focus theory of normative conduct: A theoretical refinement and re-evaluation of the role of norms in human behaviour. Advances in Experimental Social Psychology, 21, 201-234.

Devine, P. G., \& Zuwerink, J. R. (1994). Prejudice and guilt: The internal struggle to overcome prejudice. In W. J. Lonner, \& R. S. Malpass (Eds.), Psychology and culture (pp. 203-207). Boston: Allyn \& Bacon.

Devine, P. G., Monteith, M. J., Zuwerink, J. R., \& Elliot, A. J. (1991). Prejudice with and without compunction. Journal of Personality and Social Psychology, 60, 817-830.

Doosje, B., Ellemers, N., \& Spears, R. (1995). Perceived intragroup variability as a function of group status and identification. Journal of Experimental Social Psychology, 31, 410-436.

Higgins, E. T. (1987). Self-discrepancy: A theory relating self and affect. Psychological Review, 94, 319-340.

LeVine, R. A., \& Campbell, D. T. (1972). Ethnocentrism: Theories of conflict, ethnic attitudes and group behaviour. New York: Wiley.

Monteith, M. J. (1993). Self-regulation of prejudiced responses. Implications for progress in prejudice reduction efforts. Journal of Personality and Social Psychology, 65, 469-485.

Monteith, M. J. (1996). Contemporary forms of prejudice related conflict: In search of a nutshell. Personality and Social Psychology Bulletin, 22, 461-473.

Monteith, M. J., Devine, P. G., \& Zuwerink, J. R. (1993). Self-directed versus other-directed affect as a consequence of prejudice-related discrepancies. Journal of Personality and Social Psychology, 68, 198-210.

Sherif, M., \& Sherif, C. W. (1953). Groups in harmony and tension: An integration of studies on intergroup relations. New York: Harper.

Sherif, M., Harvey, O. J., White, B. J., Hood, W. R., \& Sherif, C. (1961). Intergroup cooperation and conflict: The Robber's Cave experiment. Norman, OK: University of Oklahoma Press.

Smith, E. R. (1993). Social identity and social emotions: Toward new conceptualisations of prejudice. In D. M. Mackie, \& D. L. Hamilton (Eds.), Affect, cognition and stereotyping: Interactive processes in group perception (pp. 297-315). San Diego, CA: Academic Press.

Spears, R., Doosje, B., \& Ellemers, N. (1997). Self-stereotyping in the face of threats to group status and distinctiveness: The role of Group identification. Personality and Social Psychology Bulletin, 23, 538-553.

Terry, D. J., \& Hogg, M. A. (1996). Group norms and the attitude-behaviour relationship: A role for group identification. Personality and Social Psychology Bulletin, 22, 776-793.

Turner, J. C., Hogg, M. A., Oakes, P. J., Reicher, S. D., \& Wetherell, M. S. (1987). Rediscovering the social group: A self-categorization theory. Oxford, England: Basil Blackwell.

Zuwerink, J. R., Devine, P. G., Monteith, M. J., \& Cook, D. A. (1996). Prejudice toward Blacks: With or without compunctions? Basic and Applied Social Psychology, 18, 131-150. 